\title{
Lactobacillus reuteri in Its Biofilm State Improves Protection from Experimental Necrotizing Enterocolitis
}

\author{
Ameer Al-Hadidi ${ }^{1}{ }^{(}$, Jason Navarro ${ }^{2}\left(\mathbb{D}\right.$, Steven D. Goodman ${ }^{2}$, Michael T. Bailey ${ }^{2}$ and Gail E. Besner ${ }^{1, *}$ \\ 1 Department of Pediatric Surgery, Nationwide Children's Hospital, The Ohio State University College of \\ Medicine, Center for Perinatal Research, The Research Institute at Nationwide Children's Hospital, \\ Nationwide Children's Hospital, 700 Children's Drive, Columbus, OH 43205, USA; \\ ameer.al-hadidi@nationwidechildrens.org \\ 2 Center for Microbial Pathogenesis, The Research Institute at Nationwide Children's Hospital, \\ 700 Children's Drive, Columbus, OH 43205, USA; Jason.navarro@gmail.com (J.N.); \\ Steven.goodman@nationwidechildrens.org (S.D.G.); Michael.bailey2@nationwidechildrens.org (M.T.B.) \\ * Correspondence: Gail.Besner@nationwidechildrens.org; Tel.: +1-614-722-3914
}

Citation: Al-Hadidi, A.; Navarro, J.; Goodman, S.D.; Bailey, M.T.; Besner, G.E. Lactobacillus reuteri in Its Biofilm State Improves Protection from Experimental Necrotizing Enterocolitis. Nutrients 2021, 13, 918. https://doi.org/10.3390/nu13030918

Academic Editor: M. Andrea

Azcarate-Peril

Received: 29 January 2021

Accepted: 10 March 2021

Published: 12 March 2021

Publisher's Note: MDPI stays neutral with regard to jurisdictional claims in published maps and institutional affiliations.

Copyright: (c) 2021 by the authors. Licensee MDPI, Basel, Switzerland. This article is an open access article distributed under the terms and conditions of the Creative Commons Attribution (CC BY) license (https:// creativecommons.org/licenses/by/ $4.0 /)$.

\begin{abstract}
Necrotizing enterocolitis (NEC) is a devastating disease predominately found in premature infants that is associated with significant morbidity and mortality. Despite decades of research, medical management with broad spectrum antibiotics and bowel rest has remained relatively unchanged, with no significant improvement in patient outcomes. The etiology of NEC is multi-factorial; however, gastrointestinal dysbiosis plays a prominent role in a neonate's vulnerability to and development of NEC. Probiotics have recently emerged as a new avenue for NEC therapy. However, current delivery methods are associated with potential limitations, including the need for at least daily administration in order to obtain any improvement in outcomes. We present a novel formulation of enterally delivered probiotics that addresses the current limitations. A single enteral dose of Lactobacillus reuteri delivered in a biofilm formulation increases probiotic survival in acidic gastric conditions, increases probiotic adherence to gastrointestinal epithelial cells, and reduces the incidence, severity, and neurocognitive sequelae of NEC in experimental models.
\end{abstract}

Keywords: necrotizing enterocolitis; prematurity; Lactobacillus reuteri; probiotics; dextranomer microspheres

\section{Introduction}

Necrotizing enterocolitis (NEC) is a disease that has been a major source of morbidity and mortality for premature neonates for decades. Affecting $10 \%$ of infants with birth weight $<1500 \mathrm{~g}$, NEC is a neonatal intestinal disease that is manifested by excessive inflammation that may progress to tissue destruction, bacterial translocation, and sepsis. The disease carries a mortality rate as high as 20-30\% [1,2]. Despite decades of research and an estimated annual cost to the health care system of nearly USD 1 billion, NEC remains the number one cause of death from gastrointestinal disease in premature infants [2]. Thus far, treatment and attempts at prevention of NEC have remained subpar, with surviving infants often being left with debilitating morbidities including short-gut syndrome, cholestatic liver disease, and poor growth and neurodevelopmental outcomes [3,4].

The etiology of NEC is multi-factorial with prematurity, low birth weight, administration of enteral feeds, and antibiotic exposure associated with development of the disease [2,5]. Bacterial colonization of the gastrointestinal tract is essential to healthy gut development, with strong evidence indicating that gut dysbiosis plays a prominent role in patient vulnerability and development of NEC [6-10]. Large proportions of beneficial health-promoting bacteria, including Lactobacillus and Bifidobacteria species, are present in healthy full-term breast-fed infants [11-13]. Additionally, breast milk contains significant amounts of undigestible oligosaccharides that play a role as prebiotics, nurturing and promoting the growth of the favorable gut microorganisms necessary for bacterial-epithelial 
cross talk, which is crucial for nascent gut and immune system development [11,12]. Conversely, premature infants have reduced microbiome diversity and stability, with smaller proportions of beneficial bacteria including Lactobacillus and Bifidobacterium species, and increased levels of bacteria that can become pathogenic including Gammaproteobacteria (i.e., Escherichia coli, Klebsiella pneumoniae), which is evident in infants that develop NEC [10,14-20].

To counter the altered intestinal microbiome and to reduce the pathogenic bacterial colonization frequently seen in premature infants, administration of probiotics, or live microorganisms that confer a health benefit on the host, emerged as a means of NEC prevention in the late 1990s [21,22]. Since then, numerous trials evaluating the efficacy of probiotics in preventing NEC have been conducted, with some demonstrating favorable results [23,24]. Oral administration of Lactobacillus and Bifidobacterium was shown to prevent NEC in very low birth weight infants $[25,26]$, and when administered in combination with breast milk, there was greater reduction in the incidence of NEC compared to infants receiving breast milk alone [6,27]. Furthermore, using animal models of experimental NEC, probiotics have been shown to inhibit inflammation, reduce apoptosis, inhibit Toll-like receptor 4 (TLR4) activation, and protect against intestinal mucosal barrier breakdown [28-32].

However, there are significant concerns and limitations regarding the current method of probiotic administration. An acidic gastric environment, interactions with bile acids, pressure from the host immune system, and competition with commensal and pathogenic bacteria can rapidly render probiotic bacteria ineffective, with a crippled capacity to adhere to and colonize the gut $[33,34]$. Due to the inability to be retained within the host, oral administration is required daily, if not multiple times per day, to witness even a modest beneficial effect that is effectively lost upon the cessation of probiotic administration [35]. Additionally, repeated administration of oral probiotic bacteria to premature infants with compromised gut barrier function can be problematic, given the risk of inducing bacteremia or sepsis from the probiotic administered [36-39].

To overcome these concerns and limitations, we introduced a novel probiotic delivery system that delivers beneficial health-promoting Lactobacillus reuteri (ATCC 23272) in a biofilm state rather than in a free-living planktonic state [40,41]. Probiotics delivered as a biofilm, i.e., an adhered or aggregated community of bacteria that produce a self-forming protective matrix of DNA, proteins, lipids, and oligosaccharides, are more resistant to harsh environmental conditions such as acidic gastric $\mathrm{pH}$, laminar/turbulent fluid forces, anti-microbial agents, and host immune defenses compared to free-living planktonic bacteria $[42,43]$. The use of probiotics in their biofilm state has been investigated and utilized in a few conditions, including antagonizing pathogenic infections in implants and incorporation into anti-neoplastic strategies as immunoregulators [44-47]. However, the delivery of probiotics in a biofilm state is a new and innovative strategy in the management and prevention of NEC. This review describes our findings from multiple publications using our novel probiotic delivery system, as well as the potential future applications it may bring to neonatal care.

\section{Main Body}

\subsection{Novel Delivery System}

\subsubsection{Lactobacillus reuteri}

L. reuteri is a Gram-positive bacterium that is naturally found in a variety of hosts and environments, including the healthy human intestine [48-50]. L. reuteri strains commonly found in humans are divided into two clades, i.e., clade II and clade IV, that are genetically and functionally distinct [51]. L. reuteri ATCC 23272 (aka, L. reuteri DSM20016) is a clade II strain originally isolated from human breast milk that is a frequently used probiotic given its anti-inflammatory and antimicrobial properties. Anti-inflammatory abilities are in part attributable to its ability to produce histamine and diacylglycerol kinase that together lead to activation of histamine $\mathrm{H} 2$, but inhibition of histamine $\mathrm{H} 1$ recep- 
tors (respectively) [52-54]. The $\mathrm{H} 2$ receptor is highly expressed in the intestine and has anti-inflammatory effects [55]. In addition to histamine, L. reuteri folate metabolism has been linked to its anti-inflammatory properties [56], including the production of ethionine which can modify human chromatin through ethylation [57]. L. reuteri has also been shown to induce anti-inflammatory T regulatory cells, suppress T helper (Th) 1 and Th2 cytokine responses, and to alter dendritic cell activity, but the mechanisms by which this occurs are not widely understood [58-61]. Its anti-microbial abilities are due to its production of the anti-microbial compound 3-hydroxyproprionaldehyde (3-HPA), also known as reuterin [61-63]. Reuterin is efficient at inhibiting the growth of a number of gastrointestinal pathogens through induction of oxidative stress [61,63-65]. Additionally, L. reuteri has extracellular glucosyltransferase (GTF) proteins that catalyze the formation of exopolysaccharides of glucose (glucans) from disaccharide sugars (e.g., maltose or sucrose) and possess glucan binding domains, that further allows for strong binding to other glucans.

\subsubsection{Production of L. reuteri Biofilm by Adherence to Dextranomer Microspheres}

We use dextranomer microspheres (DMs) as a surface for L. reuteri attachment and biofilm formation [40]. DMs are porous, semi-permeable, biocompatible, biodegradable, non-immunogenic, non-allergic, Generally Recognized As Safe (GRAS) microspheres composed of cross-linked dextran. DMs are currently being used in several Food and Drug Administration (FDA)-approved medical products and are accepted as safe for human administration [66-68]. In order to create a probiotic biofilm, cultures of L. reuteri are introduced to DMs and undergo a brief incubation period to allow for adherence and biofilm formation (Figure 1). Importantly, known pathogens including Escherichia coli, Salmonella typhimurium, and Clostridioides difficile do not detectibly bind to DMs, thereby not providing pathobionts with a scaffold to adhere and grow [40]. Additionally, because DMs are porous, they can be preloaded with nutritious prebiotic substances that contribute to probiotic growth and promote further biofilm production. For example, disaccharides, that under regular circumstances would be promptly diluted, metabolized, and absorbed within the proximal gastrointestinal tract, will remain undiluted within the DMs and gradually diffuse out to provide their beneficial prebiotic contents at high concentrations discriminatively to the adhered probiotics. DMs are used to take advantage of L. reuteri's GTF native ability to bind to cross-linked dextran. The GTF-dependent selective binding of $L$. reuteri to DMs results in a biofilm state with: (1) enhanced binding of $L$. reuteri to intestinal epithelial cells, (2) protection against low gastric $\mathrm{pH}$, and (3) access to high concentrations of beneficial luminal substances to $L$. reuteri in order to augment its probiotic effects.
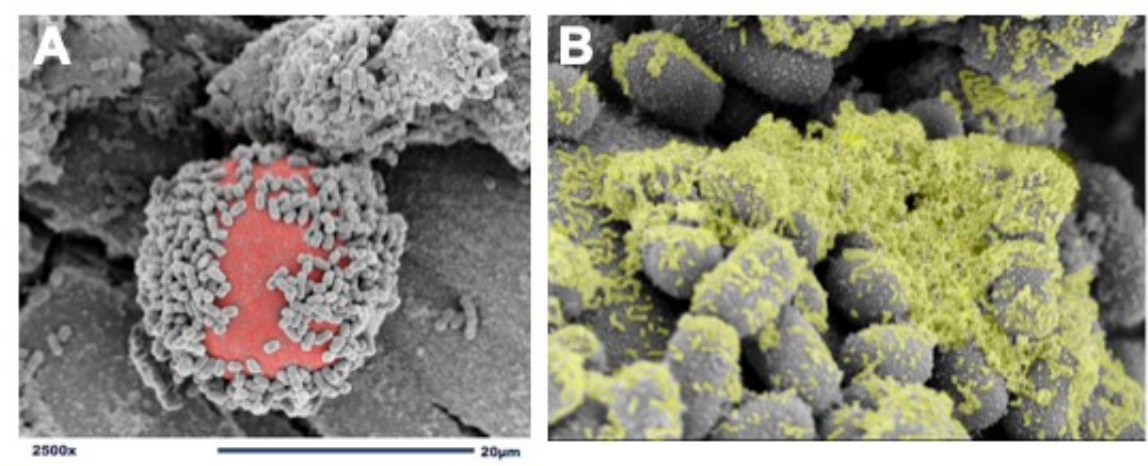

Figure 1. Adherence of L. reuteri to dextranomer microspheres. (A) scanning electron microscopy (SEM) image demonstrating the adherence of L. reuteri to the surface of a biocompatible dextranomer microsphere (DM; red); (B) magnified SEM image demonstrating the production of biofilm (green) by $L$. reuteri adhered to a sucrose-loaded DM. 


\subsection{Effects of L. reuteri in Its Biofilm State In Vitro}

\subsubsection{L. reuteri Adherence to Dextranomer Microspheres Is Dependent on GTF In Vitro}

Adherence of L. reuteri to DM is heavily GTF-dependent and is enhanced in the presence of certain disaccharides, e.g., maltose and sucrose (Table 1). Bacteria bound to $\mathrm{DM}$ are resistant to acidic conditions and have enhanced adherence to human intestinal epithelial cells [40]. In an effort to enhance L. reuteri adherence to DM, semi-permeable DMs were loaded with beneficial luminal cargo to promote improved probiotic adherence in vitro [40]. After differential staining of $L$. reuteri with a green fluorescent nucleic acid stain (SYTO9) and DMs with Congo Red, confocal laser scanning microscopy revealed significantly increased $L$. reuteri adherence to DMs containing sucrose or maltose compared to DMs containing water only [40].

Table 1. Summary of in vitro and in vivo investigations with main results.

\begin{tabular}{|c|c|c|c|c|}
\hline Article & Type of Study & Probiotic Strain & Aim of Study & Main Results \\
\hline Olson et al. 2016 [41] & In vivo & L. reuteri ATCC 23272 & $\begin{array}{l}\text { To evaluate the efficacy of a } \\
\text { novel probiotic delivery } \\
\text { system in an experimental } \\
\text { model of necrotizing } \\
\text { enterocolitis }\end{array}$ & $\begin{array}{l}\text { A single dose of L. reuteri in its } \\
\text { biofilm state significantly } \\
\text { decreased: } \\
\text { (1) the incidence of NEC } \\
(2) \quad \text { the severity of NEC } \\
\text { (3) intestinal mucosal } \\
\text { permeability } \\
\text { in premature rat pups, } \\
\text { compared to free-living, } \\
\text { planktonic L. reuteri }\end{array}$ \\
\hline Navarro et al. 2017 [40] & In vitro & L. reuteri ATCC 23272 & $\begin{array}{c}\text { To evaluate the effect of } \\
\text { enhancing a novel } L \text {. reuteri } \\
\text { biofilm formulation with the } \\
\text { addition of beneficial } \\
\text { compounds as diffusible cargo } \\
\text { within DMs }\end{array}$ & $\begin{array}{l}\text { An enhanced probiotic } \\
\text { formulation resulted in } \\
\text { increased: } \\
\text { (1) adherence of L. reuteri to } \\
\text { DMs } \\
\text { (2) resistance to acidic } \\
\text { conditions } \\
\text { (3) adherence to human } \\
\text { intestinal epithelial cells } \\
\text { in vitro }\end{array}$ \\
\hline \multirow{3}{*}{ Olson et al. 2018 [69] } & \multirow{3}{*}{ In vivo } & \multirow{3}{*}{ L. reuteri ATCC 23272} & \multirow{3}{*}{$\begin{array}{l}\text { To evaluate the efficacy of an } \\
\text { enhanced novel L. reuteri } \\
\text { biofilm formulation with } \\
\text { beneficial cargo on protection } \\
\text { from experimental NEC }\end{array}$} & $\begin{array}{l}\text { A single dose of enhanced } L \text {. } \\
\text { reuteri biofilm formulation } \\
\text { with beneficial DM cargo } \\
\text { resulted in decreased: }\end{array}$ \\
\hline & & & & $\begin{array}{ll}\text { (1) } & \text { NEC incidence and } \\
& \text { severity } \\
\text { (2) } & \text { mortality } \\
(3) & \text { intestinal permeability } \\
(4) & \text { intestinal inflammation } \\
(5) & \text { alteration in gut } \\
& \text { microbiome }\end{array}$ \\
\hline & & & & $\begin{array}{l}\text { compared to pups receiving } L \text {. } \\
\text { reuteri biofilm formulation } \\
\text { without beneficial DM cargo }\end{array}$ \\
\hline
\end{tabular}

\subsubsection{Beneficial Cargo Enhances L. reuteri Survival at Low $\mathrm{pH}$ In Vitro}

A major hindrance to the efficacy of orally consumed probiotics is the acidic nature of the stomach [70]. This is problematic given the need for viable L. reuteri to reach the distal gastrointestinal tract to be effective in preventing NEC. We investigated whether L. reuteri bound to DM would have increased survival under acidic conditions, and whether the addition of beneficial luminal cargo would further enhance survival in a GTF-dependent manner.

The viability of $L$. reuteri was evaluated after placement in synthetic gastric acid with a $\mathrm{pH}$ of 2 for $4 \mathrm{~h}$. L. reuteri in its planktonic state had a survival of $<0.1 \%$, with no significant increase in survival in the presence of sucrose or maltose, or when adhered 
to water-filled DMs. However, L. reuteri in its biofilm state adhered to DMs loaded with sucrose or maltose demonstrated significantly improved survival in the acidic environment. Notably, no significant improvement in survival was seen with a mutated $L$. reuteri strain lacking GTF, even in the presence of DM loaded with beneficial cargo [40]. These findings demonstrate the importance of GTF-dependent adherence of L. reuteri to DMs loaded with beneficial luminal cargo.

2.2.3. Beneficial Cargo Enhance L. reuteri Adherence to Human Intestinal Epithelial Cells In Vitro

We next investigated whether L. reuteri in its biofilm state adhered to DM would improve adherence of the probiotic to human DLD-1 intestinal epithelial cells (adult human colonic epithelial cells) and to FHs 74 Int cells (3-4-month gestation small intestine epithelial cells) in vitro. We also examined whether enhanced adherence was promoted by the addition of beneficial luminal cargo within DM.

When comparing wild-type L. reuteri to the GTF mutant strain, we found significantly increased binding to DLD-1 cells with wild-type L. reuteri, regardless of whether L. reuteri was delivered in its planktonic or biofilm state. This signifies the importance of GTF in adherence of the probiotic to intestinal epithelial cells. When L. reuteri was bound to DMs containing sucrose or maltose, adherence to DLD-1 cells increased by 4.7-fold and 5.2-fold, respectively. Although there was lower probiotic adherence to FHs 74 Int small intestine epithelial cells compared to colonic cells, L. reuteri in its biofilm state bound to DMs loaded with sucrose or maltose demonstrated a 1.8-fold and 2.7-fold increase in adherence, respectively, compared to L. reuteri in its planktonic state [40].

\subsection{Delivery of Lactobacillus reuteri in Its Biofilm State In Vivo}

\subsubsection{Murine Animal Model of Experimental Necrotizing Enterocolitis}

Sprague Dawley rat pups are delivered prematurely from timed-pregnant dams on gestational day 21 via terminal cesarean delivery. After delivery, pups are randomized into experimental groups that received a single $100 \mu \mathrm{L}$ enteral dose of L. reuteri $\left(2 \times 10^{8} \mathrm{CFU}\right)$, either alone or with $0.5 \mathrm{mg}$ of DM, or sterile water control treatment via gastric gavage [71]. Pups are subjected to a modification of the stress protocol initially described by Barlow et al. to induce experimental NEC $[40,41,70]$. Pups receive hypertonic formula via orogastric gavage five times daily, with exposure to hypoxia $\left(\sim 100 \%\right.$ nitrogen) and hypothermia $\left(4^{\circ} \mathrm{C}\right)$ three times daily for $90 \mathrm{~s}$ and $10 \mathrm{~min}$, respectively. Additionally, pups receive lipopolysaccharide $(2 \mathrm{mg} / \mathrm{kg}$ ) once via gastric gavage on the first day of life. Pups that develop clinical signs of NEC are euthanized with collection of intestinal tissue for histologic evaluation. After 96 h, any surviving pups are euthanized, and intestine collected. Breast-fed control pups are not exposed to experimental stresses, and are breast fed by surrogate dams. Hematoxylin and eosin (H\&E) intestinal tissue sections are graded blindly by two independent observers using an established histologic NEC injury grading system [72].

2.3.2. Lactobacillus reuteri in Its Biofilm State Protects the Intestines from Injury and Preserves Gut Barrier Function during Experimental NEC

We initially evaluated the efficacy of L. reuteri administered as a single dose shortly after delivery in preventing NEC in our experimental NEC model [41] (Table 1). Animals exposed to NEC were either untreated (receiving sterile water only) or treated with $L$. reuteri in its planktonic state (L. reuteri alone), DM alone, or L. reuteri in its biofilm state (L. reuteri $+\mathrm{DM})$. The only significant decrease in the incidence of NEC was seen with pups receiving $L$. reuteri in biofilm state. In addition, differences in intestinal mucosal permeability were evaluated by quantifying systemic absorption of enterally administered fluorescein isothiocyanate (FITC) labeled dextran [31]. FITC-dextran (1500 mg/kg) was administered to pups 48-h following cesarean delivery. Four hours after administration, pups were euthanized and serum FITC-dextran levels analyzed. Increased levels of serum FITC-dextran are indicative of increased intestinal permeability and impaired gut barrier function. Pups exposed to NEC that were untreated (receiving sterile water only) had sig- 
nificantly increased intestinal permeability compared to breast-fed control pups. Only pups exposed to NEC that were treated with L. reuteri in its biofilm state demonstrated significant reduction in intestinal permeability, indicative of improved gut barrier function [41]. Thus, a single dose of enterally administered L. reuteri in its biofilm state significantly decreased the incidence of NEC and improved gut barrier function, in a murine model of experimental NEC.

2.3.3. Enhancing Lactobacillus reuteri Biofilm Formation Increases Protection against Experimental NEC, Improves Survival, Preserves Gut Barrier Function, Decreases Proinflammatory Cytokine Production, and Preserves Eubiosis during Experimental NEC

Our in vitro studies showed that L. reuteri in its biofilm state bound to DMs loaded with sucrose or maltose demonstrated enhanced survival at low $\mathrm{pH}$ and greater adherence to intestinal epithelial cells (Table 1). Based on this, we hypothesized that enhanced biofilm formation would translate to a more pronounced decrease in NEC incidence and severity with improved survival of rat pups in our experimental NEC model [69]. When the $L$. reuteri biofilm formulation containing beneficial cargo was introduced to the model, there was a marked decrease in NEC incidence in the rat pups receiving the formulation [69]. Approximately $61 \%$ of pups receiving no treatment developed NEC, with no significant decrease in the incidence of NEC in pups receiving a single dose of L. reuteri in its planktonic state, or in pups receiving DM loaded with sucrose alone. As previously demonstrated, pups receiving L. reuteri in its biofilm state bound to DMs without beneficial luminal cargo had a significant decrease in the incidence of NEC to $33 \%$. Furthermore, pups receiving L. reuteri in its biofilm state bound to DMs containing sucrose or maltose, where biofilm formation is further enhanced, demonstrated substantial further improvement in protection against NEC, with NEC incidences decreased to $14 \%$ and $15 \%$, respectively $(p<0.05)$. This improvement translated to enhanced survival, with nearly $60 \%$ of rat pups treated with $L$. reuteri in its biofilm state bound to DMs containing luminal sucrose or maltose surviving until the end of the 96-h protocol, whereas only $20 \%$ of untreated stressed pups survived [69]. No significant improvement in survival was appreciated in pups receiving L. reuteri in its planktonic form, or in pups receiving DM loaded with sucrose or maltose alone. Furthermore, any significant protective effect seen with $L$. reuteri was absent when a GtfW mutated strain was administered, even in the presence of DMs loaded with beneficial cargo.

To investigate gut barrier function, $48 \mathrm{~h}$ after initiating the experimental NEC protocol, rat pups received enteral FITC-dextran. Four hours after administration, pups were euthanized and serum FD70 levels analyzed. Untreated pups experienced significantly increased intestinal permeability compared to breast-fed control pups $(p=0.001)$ [69]. Pups treated with a single dose of $L$. reuteri in its biofilm state bound to DMs containing sucrose or maltose had significantly reduced intestinal permeability compared to untreated pups ( $p=0.009$ and 0.006 , respectively), indicating improved gut barrier function. Pups treated with a single dose L. reuteri in its planktonic state did not demonstrate improved gut barrier function.

We next examined the expression of inflammatory cytokines interleukin (IL)-6, IL-1B, chemokine ligand (CCL)-2, CXCL-1, and IL-10 in intestinal specimens from the different treatment groups. Pups exposed to NEC receiving no treatment demonstrated significant elevation in the expression of IL-6, IL-1B, CCL-2, CXCL-1, and IL-10 in the small intestine compared to unstressed breast-fed rat pups $(p<0.002)$ [69]. Pups receiving a single treatment dose of $L$. reuteri in its biofilm state bound to DMs containing sucrose or maltose had significantly lower expression of IL-6, IL-1B, CCL-2, CXCL-1, and IL-10 compared to untreated pups, or to pups treated with $L$. reuteri in its planktonic form $(p<0.05)$. The decrease in production of pro-inflammatory compounds is likely secondary to the intrinsic ability of $L$. reuteri to produce histamine, which suppresses pro-inflammatory cytokine production, in synergy with a biofilm state allowing for an enhanced anti-inflammatory effect. Further investigation is required as discussed in Section 2.4. 
The gut microbiota community structure and taxa composition of pups treated with $L$. reuteri in its biofilm compared to its planktonic state were investigated using 16S rRNA gene sequencing analysis [69]. Unweighted UniFrac analysis demonstrated distinctive clustering between unstressed pups, stressed pups treated with L. reuteri in its biofilm state bound to DMs containing maltose, and stressed pups treated with L. reuteri in its planktonic state. Notably, the microbiota community arrangement of pups treated with L. reuteri in its biofilm state clustered more closely with unstressed, vaginally delivered, breast-fed pups. Furthermore, taxa-level analysis demonstrated that Lactobacillus species abundance was more effectively maintained and closely related to unstressed, breast-fed controls in pups treated with L. reuteri in its biofilm state compared to its planktonic state $(p<0.05)$. In addition, Lactobacillus species abundance was inversely associated with NEC injury (Pearson $r=-0.480, p=0.01$ ). Both the biofilm and planktonic formulations of $L$. reuteri effectively limited the abundance of Enterobacter species, a potential enteric pathogen, compared to unstressed pups and untreated stressed pups $(p<0.05)$.

\subsubsection{Decreasing L. reuteri Biofilm Production Decreases Protection from NEC}

The ability of $L$. reuteri to adhere and form a biofilm is GTF-dependent and essential to provide intestinal protection from NEC. An experiment comparing the ability of wild type L. reuteri versus GTF-deficient $L$. reuteri in preventing NEC was conducted. Compared to untreated stressed pups, pups receiving $L$. reuteri $+\mathrm{DM}$ loaded with maltose had a significantly lower incidence of NEC (65\% vs. 22\%, $p<0.05)$ [69]. However, pups receiving mutant $L$. reuteri deficient in GTF (blunted biofilm forming capacity), even in combination with DMs, failed to demonstrate any significant decrease in NEC incidence compared to untreated pups $(p>0.05)$, signifying the importance of GTF-dependent biofilm formation in the prevention of NEC.

\subsection{Future Investigations of L. reuteri to Better Understand Protective Properties and Long-Term Outcomes}

2.4.1. Utilization of L. reuteri Mutants to Better Understand the Properties of L. reuteri That Lead to Intestinal Protection from NEC In Vivo

L. reuteri possesses anti-inflammatory and antimicrobial properties which we suspect play an integral role in intestinal protection from NEC. L. reuteri's ability to produce histamine from L-histidine is believed to play a crucial role in anti-inflammation, as histamine suppresses tissue necrosis factor (TNF) production [53,61,73-75]. Future experiments will include: (1) administered of L. reuteri with DMs loaded with L-histidine (to augment anti-inflammatory production) and (2) utilizing a histamine-deficient mutant of L. reuteri (to attenuate anti-inflammatory production). Both experiments will be investigated in an animal model to evaluate the effect that increased or decreased histamine production has on intestinal protection from NEC.

L. reuteri also possesses antimicrobial properties due to its ability to produce reuterin $[61,64]$. Reuterin has been shown to effectively inhibit pathogenic bacterial growth through the induction of oxidative stress [64]. Future experiments will include utilizing a reuterin-deficient mutant of $L$. reuteri to evaluate whether intestinal protection from NEC is attenuated in the absence of reuterin.

\subsubsection{Lactobacillus reuteri in Its Biofilm State Has Potential to Attenuate Neurocognitive Injury after Experimental NEC}

Over $40 \%$ of NEC survivors are left with debilitating life-long neurocognitive and developmental impairments [76,77]. These include development of cerebral palsy, or other cognitive, psychomotor, auditory, and visual disabilities that result in lower cognitive ability, educational achievement, and inferior mental health compared to age-matched NICU patients without NEC [78-81]. It is well recognized that premature infants suffering from intestinal injury can have abnormal neurodevelopment; however, the etiology remains unclear and likely multifactorial [78]. Associations have been made between gut microbiota and brain function, with dysbiosis in preterm infants after NEC and/or sepsis being 
linked to poor neurologic outcomes [78-82]. Multiple routes of communication exist for bidirectional gut-to-brain communication (neuronal, immune, metabolic and endocrine) and they all physiologically intersect with the gut microbiome. Thus, treatments that target the gut microbiome may improve cognitive disorders while addressing underlying intestinal injury.

There is increasing evidence suggesting that decreased myelination is largely responsible for the neurodevelopmental sequelae and white matter abnormalities in survivors of NEC [83-86]. Microglia are the macrophages of the brain and have a role in immune defense and brain homeostasis $[87,88]$. The activation of microglia triggered by proinflammatory cytokines results in loss of oligodendrocyte precursor cells accountable for neuronal myelination, leading to diminished myelination with cognitive impairment following NEC [83-86]. As mentioned above, we previously demonstrated the ability $L$. reuteri in its biofilm state to down-regulate the expression of proinflammatory cytokines and up-regulate the expression of anti-inflammatory compounds such as histamine [69]. Future investigations will explore whether a single enterally administered dose of $L$. reuteri in its biofilm state can attenuate microglial activation, preserve neuronal myelination, and protect against neurocognitive injury in rat pups surviving our experimental NEC model.

\section{Conclusions}

Necrotizing enterocolitis continues to be a major source of morbidity and mortality for premature infants. Despite years of research and advancements in critical care, improvement in the outcomes of infants suffering from NEC are subtle at best. Probiotics have shown promise as a potential treatment to reduce the incidence and severity of NEC; however, current delivery methods present legitimate concerns. Our proposed method of delivering a single enteral dose of the probiotic Lactobacillus reuteri in a biofilm formulation alleviates most of these concerns. Investigations using our experimental animal model have demonstrated the ability of our L. reuteri biofilm formulation to significantly reduce the incidence and severity of NEC, decrease NEC-related mortality, stabilize the intestinal mucosal barrier, and down-regulate the production of proinflammatory cytokines. Given the effects of NEC and of gut microbes on infant neurodevelopment, future studies will determine whether our enhanced probiotic formulation will help prevent the deleterious effects of NEC on neurocognitive development.

Since probiotics offer a potential benefit in other infectious or inflammatory conditions, additional investigation is underway for the use of our enhanced probiotic formulation in the treatment and management of several other gastrointestinal diseases, including Clostridioides difficile colitis [89] and inflammatory bowel disease.

Author Contributions: Conceptualization, A.A.-H., G.E.B., S.D.G., M.T.B.; methodology, A.A.-H., G.E.B., S.D.G., M.T.B.; formal analysis, A.A.-H., G.E.B., S.D.G., M.T.B.; investigation, A.A.-H.; J.N resources, G.E.B., S.D.G., M.T.B.; data curation, A.A.-H.; original draft preparation, A.A.-H.; review and editing, G.E.B., S.D.G., M.T.B.; supervision, G.E.B.; project administration, G.E.B.; funding acquisition, G.E.B., S.D.G., M.T.B. All authors have read and agreed to the published version of the manuscript.

Funding: This research was funded by NIH R01 GM123482 (G.E.B., S.D.G., M.T.B.).

Institutional Animal Care and Use Committee Statement: All animal studies were conducted in compliance with protocol \#AR15-00012 approved by the Institutional Animal Care and Use Committee of The Research Institute at Nationwide Children's Hospital.

Informed Consent Statement: Not applicable.

Data Availability Statement: Data is contained within the article or supplementary material. The data presented in this manuscript are available in Olson et al. 2016 [41], Navarro et al. 2017 [40], and Olson et al. 2018 [69].

Acknowledgments: The authors would like to thank Yijie Wang (Nationwide Children's Hospital, Laboratory of Gail Besner), Miriam Conces (Nationwide Children's Hospital, Department of Pathol- 
ogy), and Cynthia McAllister (Nationwide Children's Hospital, Morphology Core) for playing an integral role in production of the presented scientific data.

Conflicts of Interest: G.B., S.D.G. and M.T.B. have stock options in Scioto Biosciences, Inc.

\section{References}

1. Henry, M.C.W.; Moss, R.L. Necrotizing Enterocolitis. Annu. Rev. Med. 2009, 60, 111-124. [CrossRef] [PubMed]

2. Neu, J.; Walker, W.A. Necrotizing Enterocolitis. N. Eng. J. Med. 2011, 364, 255-264. [CrossRef]

3. Petty, J.K.; Ziegler, M.M. Operative strategies for necrotizing enterocolitis: The prevention and treatment of short-bowel syndrome. Semin. Pediatr. Surg. 2005, 14, 191-198. [CrossRef] [PubMed]

4. Ganguli, K.; Walker, W.A. Probiotics in the Prevention of Necrotizing Enterocolitis. J. Clin. Gastroenterol. 2011, 45, S133-S138. [CrossRef] [PubMed]

5. Hackam, D.J.; Good, M.; Sodhi, C.P. Mechanisms of gut barrier failure in the pathogenesis of necrotizing enterocolitis: Toll-like receptors throw the switch. Semin. Pediatr. Surg. 2013, 22, 76-82. [CrossRef] [PubMed]

6. Grölund, M.-M.; Lehtonen, O.-P.; Eerola, E.; Kero, P. Fecal Microflora in Healthy Infants Born by Different Methods of Delivery: Permanent Changes in Intestinal Flora After Cesarean Delivery. J. Pediatr. Gastroenterol. Nutr. 1999, 28, 19-25. [CrossRef] [PubMed]

7. Harmsen, H.J.M.; Wildeboer-Veloo, A.C.M.; Raangs, G.C.; Wagendorp, A.A.; Klijn, N.; Bindels, J.G.; Welling, G.W. Analysis of Intestinal Flora Development in Breast-Fed and Formula-Fed Infants by Using Molecular Identification and Detection Methods. J. Pediatr. Gastroenterol. Nutr. 2000, 30, 61-67. [CrossRef] [PubMed]

8. Mai, V.; Young, C.M.; Ukhanova, M.; Wang, X.; Sun, Y.; Casella, G.; Theriaque, D.; Li, N.; Sharma, R.; Hudak, M.; et al. Fecal Microbiota in Premature Infants Prior to Necrotizing Enterocolitis. PLoS ONE 2011, 6, e20647. [CrossRef] [PubMed]

9. Morrow, A.L.; Lagomarcino, A.J.; Schibler, K.R.; Taft, D.H.; Yu, Z.; Wang, B.; Altaye, M.; Wagner, M.; Gevers, D.; Ward, D.V.; et al. Early microbial and metabolomic signatures predict later onset of necrotizing enterocolitis in preterm infants. Microbiome 2013, 1, 1-16. [CrossRef] [PubMed]

10. Warner, B.B.; Deych, E.; Zhou, Y.; Hall-Moore, C.; Weinstock, G.M.; Sodergren, E.; Shaikh, N.; Hoffmann, J.A.; Linneman, L.A.; Hamvas, A.; et al. Gut bacteria dysbiosis and necrotising enterocolitis in very low birthweight infants: A prospective case-control study. Lancet 2016, 387, 1928-1946. [CrossRef]

11. Weng, M.; Walker, W.A. The role of gut microbiota in programming the immune phenotype. J. Dev. Orig. Health Dis. 2013, 4 , 203-214. [CrossRef] [PubMed]

12. Guarner, F.; Khan, A.G.; Garisch, J.; Eliakim, R.; Gangl, A.; Thomson, A.; Krabshuis, J.; Lemair, T.; Kaufmann, P.; De Paula, J.A.; et al. World Gastroenterology Organisation Global Guidelines. J. Clin. Gastroenterol. 2012, 46, 468-481. [CrossRef] [PubMed]

13. Kleessen, B.; Bunke, H.; Tovar, K.; Noack, J.; Sawatzki, G. Influence of two infant formulas and human milk on the development of the faecal flora in newborn infants. Acta Paediatr. 1995, 84, 1347-1356. [CrossRef] [PubMed]

14. Mshvildadze, M.; Neu, J.; Mai, V. Intestinal microbiota development in the premature neonate: Establishment of a lasting commensal relationship? Nutr. Rev. 2008, 66, 658-663. [CrossRef]

15. Groer, M.W.; A Luciano, A.; Dishaw, L.J.; Ashmeade, T.L.; Miller, E.; A Gilbert, J. Development of the preterm infant gut microbiome: A research priority. Microbiome 2014, 2, 38. [CrossRef] [PubMed]

16. Berrington, J.E.; Stewart, C.J.; Embleton, N.D.; Cummings, S.P. Gut microbiota in preterm infants: Assessment and relevance to health and disease. Arch. Dis. Child. Fetal Neonatal Ed. 2013, 98, F286-F290. [CrossRef] [PubMed]

17. Cassir, N.; Simeoni, U.; La Scola, B. Gut microbiota and the pathogenesis of necrotizing enterocolitis in preterm neonates. Future Microbiol. 2016, 11, 273-292. [CrossRef] [PubMed]

18. Grishin, A.; Papillon, S.; Bell, B.; Wang, J.; Ford, H.R. The role of the intestinal microbiota in the pathogenesis of necrotizing enterocolitis. Semin. Pediatr. Surg. 2013, 22, 69-75. [CrossRef] [PubMed]

19. Pammi, M.; Cope, J.; Tarr, P.I.; Warner, B.B.; Morrow, A.L.; Mai, V.; Gregory, K.E.; Kroll, J.S.; McMurtry, V.; Ferris, M.J.; et al. Intestinal dysbiosis in preterm infants preceding necrotizing enterocolitis: A systematic review and meta-analysis. Microbiome 2017, 5, 1-15. [CrossRef]

20. Wang, Y.; Hoenig, J.D.; Malin, K.J.; Qamar, S.; Petrof, E.O.; Sun, J.; Antonopoulos, D.A.; Chang, E.B.; Claud, E.C. 16S rRNA gene-based analysis of fecal microbiota from preterm infants with and without necrotizing enterocolitis. ISME J. 2009, 3, 944-954. [CrossRef] [PubMed]

21. Hoyos, A.B. Reduced incidence of necrotizing enterocolitis associated with enteral administration of Lactobacillus acidophilus and Bifidobacterium infantis to neonates in an intensive care unit. Int. J. Infect. Dis. 1999, 3, 197-202. [CrossRef]

22. Reid, G.; Jass, J.; Sebulsky, M.T.; McCormick, J.K. Potential Uses of Probiotics in Clinical Practice. Clin. Microbiol. Rev. 2003, 16, 658-672. [CrossRef] [PubMed]

23. Wang, Q.; Dong, J.; Zhu, Y. Probiotic supplement reduces risk of necrotizing enterocolitis and mortality in preterm very low-birth-weight infants: An updated meta-analysis of 20 randomized, controlled trials. J. Pediatr. Surg. 2012, 47, 241-248. [CrossRef] [PubMed]

24. AlFaleh, K.; Anabrees, J. Probiotics for prevention of necrotizing enterocolitis in preterm infants. Cochrane Database Syst. Rev. 2014, CD005496. [CrossRef]

25. Bin-Nun, A.; Bromiker, R.; Wilschanski, M.; Kaplan, M.; Rudensky, B.; Hammerman, C. Oral Probiotics Prevent Necrotizing Enterocolitis in Very Low Birth Weight Neonates. J. Pediatr. 2005, 147, 192-196. [CrossRef] [PubMed] 
26. Braga, T.D.; Da Silva, G.A.P.; De Lira, P.I.C.; Lima, M.D.C. Efficacy of Bifidobacterium breve and Lactobacillus casei oral supplementation on necrotizing enterocolitis in very-low-birth-weight preterm infants: A double-blind, randomized, controlled trial. Am. J. Clin. Nutr. 2010, 93, 81-86. [CrossRef] [PubMed]

27. Lin, H.-C.; Hsu, C.-H.; Chen, H.-L.; Chung, M.-Y.; Hsu, J.-F.; Lien, R.-I.; Tsao, L.-Y.; Chen, C.-H.; Su, B.-H. Oral Probiotics Prevent Necrotizing Enterocolitis in Very Low Birth Weight Preterm Infants: A Multicenter, Randomized, Controlled Trial. Pediatrics 2008, 122, 693-700. [CrossRef] [PubMed]

28. Good, M.; Sodhi, C.P.; Ozolek, J.A.; Buck, R.H.; Goehring, K.C.; Thomas, D.L.; Vikram, A.; Bibby, K.; Morowitz, M.J.; Firek, B.; et al. Lactobacillus rhamnosus HN001 decreases the severity of necrotizing enterocolitis in neonatal mice and preterm piglets: Evidence in mice for a role of TLR9. Am. J. Physiol. Liver Physiol. 2014, 306, G1021-G1032. [CrossRef] [PubMed]

29. Underwood, M.A.; Arriola, J.; Gerber, C.W.; Kaveti, A.; Kalanetra, K.M.; Kananurak, A.; Bevins, C.L.; Mills, D.A.; Dvorak, B. Bifidobacterium longum subsp. infantis in experimental necrotizing enterocolitis: Alterations in inflammation, innate immune response, and the microbiota. Pediatr. Res. 2014, 76, 326-333. [CrossRef] [PubMed]

30. Weng, M.; Ganguli, K.; Zhu, W.; Shi, H.N.; Walker, W.A. Conditioned medium from Bifidobacteria infantis protects against Cronobacter sakazakii-induced intestinal inflammation in newborn mice. Am. J. Physiol. Liver Physiol. 2014, 306, G779-G787. [CrossRef] [PubMed]

31. Bergmann, K.R.; Liu, S.X.; Tian, R.; Kushnir, A.; Turner, J.R.; Li, H.-L.; Chou, P.M.; Weber, C.R.; De Plaen, I.G. Bifidobacteria Stabilize Claudins at Tight Junctions and Prevent Intestinal Barrier Dysfunction in Mouse Necrotizing Enterocolitis. Am. J. Pathol. 2013, 182, 1595-1606. [CrossRef] [PubMed]

32. Arciero, J.; Ermentrout, G.B.; Siggers, R.; Afrazi, A.; Hackam, D.; Vodovotz, Y.; Rubin, J. Modeling the interactions of bacteria and Toll-like receptor-mediated inflammation in necrotizing enterocolitis. J. Theor. Biol. 2013, 321, 83-99. [CrossRef] [PubMed]

33. Ding, W.; Shah, N. Acid, Bile, and Heat Tolerance of Free and Microencapsulated Probiotic Bacteria. J. Food Sci. 2007, 72, M446-M450. [CrossRef] [PubMed]

34. Alander, M.; Satokari, R.; Korpela, R.; Saxelin, M.; Vilpponen-Salmela, T.; Mattila-Sandholm, T.; Von Wright, A. Persistence of Colonization of Human Colonic Mucosa by a Probiotic Strain, Lactobacillus rhamnosus GG, after Oral Consumption. Appl. Environ. Microbiol. 1999, 65, 351-354. [CrossRef] [PubMed]

35. Mackos, A.R.; Galley, J.D.; Eubank, T.D.; Easterling, R.S.; Parry, N.M.; Fox, J.G.; Lyte, M.; Bailey, M.T. Social stress-enhanced severity of Citrobacter rodentium-induced colitis is CCL2-dependent and attenuated by probiotic Lactobacillus reuteri. Mucosal Immunol. 2016, 9, 515-526. [CrossRef] [PubMed]

36. De Groote, M.A.; Frank, D.N.; Dowell, E.; Glode, M.P.; Pace, N.R. Lactobacillus rhamnosus gg bacteremia associated with probiotic use in a child with short gut syndrome. Pediatr. Infect. Dis. J. 2005, 24, 278-280. [CrossRef] [PubMed]

37. Kunz, A.N.; Noel, J.M.; Fairchok, M.P. Two Cases of Lactobacillus Bacteremia During Probiotic Treatment of Short Gut Syndrome. J. Pediatr. Gastroenterol. Nutr. 2004, 38, 457-458. [CrossRef] [PubMed]

38. Land, M.H.; Rouster-Stevens, K.; Woods, C.R.; Cannon, M.L.; Cnota, J.; Shetty, A.K. Lactobacillus sepsis associated with probiotic therapy. Pediatrics 2005, 115, 178-181. [CrossRef]

39. Salminen, M.K.; Tynkkynen, S.; Rautelin, H.; Saxelin, M.; Vaara, M.; Ruutu, P.; Sarna, S.; Valtonen, V.; Järvinen, A. Lactobacillus Bacteremia during a Rapid Increase in Probiotic Use of Lactobacillus rhamnosus GG in Finland. Clin. Infect. Dis. 2002, 35, 1155-1160. [CrossRef] [PubMed]

40. Navarro, J.B.; Mashburn-Warren, L.; Bakaletz, L.O.; Bailey, M.T.; Goodman, S.D. Enhanced Probiotic Potential of Lactobacillus reuteri When Delivered as a Biofilm on Dextranomer Microspheres That Contain Beneficial Cargo. Front. Microbiol. 2017, 8, 489. [CrossRef]

41. Olson, J.K.; Rager, T.M.; Navarro, J.B.; Mashburn-Warren, L.; Goodman, S.D.; Besner, G.E. Harvesting the benefits of biofilms: A novel probiotic delivery system for the prevention of necrotizing enterocolitis. J. Pediatr. Surg. 2016, 51, 936-941. [CrossRef] [PubMed]

42. Salas-Jara, M.J.; Ilabaca, A.; Vega, M.; García, A. Biofilm Forming Lactobacillus: New Challenges for the Development of Probiotics. Microorganisms 2016, 4, 35. [CrossRef] [PubMed]

43. Hall-Stoodley, L.; Costerton, J.W.; Stoodley, P. Bacterial biofilms: From the Natural environment to infectious diseases. Nat. Rev. Genet. 2004, 2, 95-108. [CrossRef] [PubMed]

44. Han, C.; Song, J.; Hu, J.; Fu, H.; Feng, Y.; Mu, R.; Xing, Z.; Wang, Z.; Wang, L.; Zhang, J.; et al. Smectite promotes probiotic biofilm formation in the gut for cancer immunotherapy. Cell Rep. 2021, 34, 108706. [CrossRef] [PubMed]

45. Alfarrayeh, I.; Fekete, C.; Gazdag, Z.; Papp, G. Propolis ethanolic extract has double-face in vitro effect on the planktonic growth and biofilm formation of some commercial probiotics. Saudi J. Biol. Sci. 2021, 28, 1033-1039. [CrossRef] [PubMed]

46. Tan, L.; Fu, J.; Feng, F.; Liu, X.; Cui, Z.; Li, B.; Han, Y.; Zheng, Y.; Yeung, K.W.K.; Li, Z.; et al. Engineered probiotics biofilm enhances osseointegration via immunoregulation and anti-infection. Sci. Adv. 2020, 6, eaba5723. [CrossRef] [PubMed]

47. Wu, D.; Li, X.; Yu, Y.; Gong, B.; Zhou, X. Heparin stimulates biofilm formation of Escherichia coli strain Nissle 1917. Biotechnol. Lett. 2021, 43, 235-246. [CrossRef] [PubMed]

48. Reuter, G. The Lactobacillus and Bifidobacterium microflora of the human intestine: Composition and succession. Curr. Issues Intest. Microbiol. 2001, 2, 43-53. [PubMed]

49. Urbańska, M.; Szajewska, H. The efficacy of Lactobacillus reuteri DSM 17938 in infants and children: A review of the current evidence. Eur. J. Nucl. Med. Mol. Imaging 2014, 173, 1327-1337. [CrossRef] [PubMed] 
50. Valeur, N.; Engel, P.; Carbajal, N.; Connolly, E.; Ladefoged, K. Colonization and Immunomodulation by Lactobacillus reuteri ATCC 55730 in the Human Gastrointestinal Tract. Appl. Environ. Microbiol. 2004, 70, 1176-1181. [CrossRef] [PubMed]

51. Spinler, J.K.; Sontakke, A.; Hollister, E.B.; Venable, S.F.; Oh, P.L.; Balderas, M.A.; Saulnier, D.M.; Mistretta, T.-A.; Devaraj, S.; Walter, J.; et al. From Prediction to Function Using Evolutionary Genomics: Human-Specific Ecotypes of Lactobacillus reuteri Have Diverse Probiotic Functions. Genome Biol. Evol. 2014, 6, 1772-1789. [CrossRef]

52. Ganesh, B.P.; Hall, A.; Ayyaswamy, S.; Nelson, J.W.; Fultz, R.; Major, A.; Haag, A.; Esparza, M.; Lugo, M.; Venable, S.; et al. Diacylglycerol kinase synthesized by commensal Lactobacillus reuteri diminishes protein kinase C phosphorylation and histaminemediated signaling in the mammalian intestinal epithelium. Mucosal Immunol. 2018, 11, 380-393. [CrossRef] [PubMed]

53. Thomas, C.M.; Hong, T.; Van Pijkeren, J.P.; Hemarajata, P.; Trinh, D.V.; Hu, W.; Britton, R.A.; Kalkum, M.; Versalovic, J. Histamine Derived from Probiotic Lactobacillus reuteri Suppresses TNF via Modulation of PKA and ERK Signaling. PLoS ONE 2012, 7, e31951. [CrossRef] [PubMed]

54. Hemarajata, P.; Gao, C.; Pflughoeft, K.J.; Thomas, C.M.; Saulnier, D.M.; Spinler, J.K.; Versalovic, J. Lactobacillus reuteri-Specific Immunoregulatory Gene rsiR Modulates Histamine Production and Immunomodulation by Lactobacillus reuteri. J. Bacteriol. 2013, 195, 5567-5576. [CrossRef] [PubMed]

55. Gao, C.; Major, A.; Rendon, D.; Lugo, M.; Jackson, V.; Shi, Z.; Mori-Akiyama, Y.; Versalovic, J. Histamine H2 Receptor-Mediated Suppression of Intestinal Inflammation by Probiotic Lactobacillus reuteri. mBio 2015, 6, e01358-15. [CrossRef] [PubMed]

56. Thomas, C.M.; Saulnier, D.M.A.; Spinler, J.K.; Hemarajata, P.; Gao, C.; Jones, S.E.; Grimm, A.; Balderas, M.A.; Burstein, M.D.; Morra, C.; et al. FolC2-mediated folate metabolism contributes to suppression of inflammation by probiotic Lactobacillus reuteri. Microbiology 2016, 5, 802-818. [CrossRef] [PubMed]

57. Röth, D.; Chiang, A.J.; Hu, W.; Gugiu, G.B.; Morra, C.N.; Versalovic, J.; Kalkum, M. Two-carbon folate cycle of commensal Lactobacillus reuteri 6475 gives rise to immunomodulatory ethionine, a source for histone ethylation. FASEB J. 2018, 33, 3536-3548. [CrossRef] [PubMed]

58. Karimi, K.; Inman, M.D.; Bienenstock, J.; Forsythe, P. Lactobacillus reuteri-Induced Regulatory T cells Protect against an Allergic Airway Response in Mice. Am. J. Respir. Crit. Care Med. 2009, 179, 186-193. [CrossRef] [PubMed]

59. Poutahidis, T.; Kleinewietfeld, M.; Smillie, C.; Levkovich, T.; Perrotta, A.; Bhela, S.; Varian, B.J.; Ibrahim, Y.M.; Lakritz, J.R.; Kearney, S.M.; et al. Microbial Reprogramming Inhibits Western Diet-Associated Obesity. PLoS ONE 2013, 8, e68596. [CrossRef] [PubMed]

60. Engevik, M.A.; Ruan, W.; Esparza, M.; Fultz, R.; Shi, Z.; Engevik, K.A.; Engevik, A.C.; Ihekweazu, F.D.; Visuthranukul, C.; Venable, S.; et al. Immunomodulation of dendritic cells by Lactobacillus reuteri surface components and metabolites. Physiol. Rep. 2021, 9, e14719. [CrossRef] [PubMed]

61. E Jones, S.; Versalovic, J. Probiotic Lactobacillus reuteri biofilms produce antimicrobial and anti-inflammatory factors. BMC Microbiol. 2009, 9, 35. [CrossRef] [PubMed]

62. Talarico, T.L.; A Casas, I.; Chung, T.C.; Dobrogosz, W.J. Production and isolation of reuterin, a growth inhibitor produced by Lactobacillus reuteri. Antimicrob. Agents Chemother. 1988, 32, 1854-1858. [CrossRef] [PubMed]

63. Dupont, A.W.; Richards, D.M.; Jelinek, K.A.; Krill, J.T.; Rahimi, E.F.; A Ghouri, Y. Systematic review of randomized controlled trials of probiotics, prebiotics, and synbiotics in inflammatory bowel disease. Clin. Exp. Gastroenterol. 2014, 7, 473-487. [CrossRef] [PubMed]

64. Schaefer, L.; Auchtung, T.A.; Hermans, K.E.; Whitehead, D.; Borhan, B.; Britton, R.A. The antimicrobial compound reuterin (3-hydroxypropionaldehyde) induces oxidative stress via interaction with thiol groups. Microbiology 2010, 156, 1589-1599. [CrossRef] [PubMed]

65. Arqués, J.L.; Fernández, J.; Gaya, P.; Nuñez, M.; Rodríguez, E.; Medina, M. Antimicrobial activity of reuterin in combination with nisin against food-borne pathogens. Int. J. Food Microbiol. 2004, 95, 225-229. [CrossRef]

66. Stenberg, A.; Lackgren, G. A New Bioimplant for the Endoscopic Treatment of Vesicoureteral Reflux: Experimental and Short-term Clinical Results. J. Urol. 1995, 154, 800-803. [CrossRef]

67. Jacobsson, S.; Jonsson, L.; Rank, F.; Rothman, U. Studies on Healing of Debrisan-Treated Wounds. Scand. J. Plast. Reconstr. Surg. 1976, 10, 97-101. [CrossRef] [PubMed]

68. Hoy, S.M. Dextranomer in Stabilized Sodium Hyaluronate (Solesta ${ }^{\circledR}$ ). Drugs 2012, 72, 1671-1678. [CrossRef]

69. Olson, J.K.; Navarro, J.B.; Allen, J.M.; McCulloh, C.J.; Mashburn-Warren, L.; Wang, Y.; Varaljay, V.A.; Bailey, M.T.; Goodman, S.D.; Besner, G.E. An enhanced Lactobacillus reuteri biofilm formulation that increases protection against experimental necrotizing enterocolitis. Am. J. Physiol. Gastrointest. Liver Physiol. 2018, 315, G408-G419. [CrossRef] [PubMed]

70. Dressman, J.B.; Berardi, R.R.; Dermentzoglou, L.C.; Russell, T.L.; Schmaltz, S.P.; Barnett, J.L.; Jarvenpaa, K.M. Upper Gastrointestinal (GI) pH in Young, Healthy Men and Women. Pharm. Res. 1990, 7, 756-761. [CrossRef] [PubMed]

71. Wu, S.-F.; Chiu, H.-Y.; Chen, A.-C.; Lin, H.-Y.; Lin, H.-C.; Caplan, M. Efficacy of Different Probiotic Combinations on Death and Necrotizing Enterocolitis in a Premature Rat Model. J. Pediatr. Gastroenterol. Nutr. 2013, 57, 23-28. [CrossRef] [PubMed]

72. Caplan, M.S.; Hedlund, E.; Adler, L.; Hsueh, W. Role of Asphyxia and Feeding in a Neonatal Rat Model of Necrotizing Enterocolitis. Pediatr. Pathol. 1994, 14, 1017-1028. [CrossRef] [PubMed]

73. Hardy, H.; Harris, J.; Lyon, E.; Beal, J.; Foey, A.D. Probiotics, Prebiotics and Immunomodulation of Gut Mucosal Defences: Homeostasis and Immunopathology. Nutrients 2013, 5, 1869-1912. [CrossRef] [PubMed]

74. McFall-Ngai, M. Adaptive immunity: Care for the community. Nature 2007, 445, 153. [CrossRef] [PubMed]

75. Yan, F.; Polk, D. Probiotics and immune health. Curr. Opin. Gastroenterol. 2011, 27, 496-501. [CrossRef] [PubMed] 
76. Matei, A.; Montalva, L.; Goodbaum, A.; Lauriti, G.; Zani, A. Neurodevelopmental impairment in necrotising enterocolitis survivors: Systematic review and meta-analysis. Arch. Dis. Child. Fetal Neonatal Ed. 2019, 105, 432-439. [CrossRef] [PubMed]

77. Moschopoulos, C.; Kratimenos, P.; Koutroulis, I.; Shah, B.V.; Mowes, A.; Bhandari, V. The neurodevelopmental perspective of surgical necrotizing enterocolitis: the role of the gut-brain axis. Mediat. Inflamm. 2018, 7456857. [CrossRef]

78. Niemarkt, H.J.; De Meij, T.G.; Van Ganzewinkel, C.J.; De Boer, N.K.H.; Andriessen, P.; Hütten, M.C.; Kramer, B.W. Necrotizing Enterocolitis, Gut Microbiota, and Brain Development: Role of the Brain-Gut Axis. Neonatology 2019, 115, 423-431. [CrossRef] [PubMed]

79. Rees, C.M.; Pierro, A.; Eaton, S. Neurodevelopmental outcomes of neonates with medically and surgically treated necrotizing enterocolitis. Arch. Dis. Child. Fetal Neonatal Ed. 2007, 92, F193-F198. [CrossRef] [PubMed]

80. Robinson, J.R.; Kennedy, C.; Van Arendonk, K.J.; Green, A.; Martin, C.R.; Blakely, M.L. Neurodevelopmental considerations in surgical necrotizing enterocolitis. Semin. Pediatr. Surg. 2018, 27, 52-56. [CrossRef] [PubMed]

81. Roze, E.; Ta, B.D.P.; Van Der Ree, M.H.; Tanis, J.C.; A Van Braeckel, K.N.J.; Hulscher, J.B.F.; Bos, A.F. Functional Impairments at School Age of Children with Necrotizing Enterocolitis or Spontaneous Intestinal Perforation. Pediatr. Res. 2011, 70, 619-625. [CrossRef] [PubMed]

82. Underwood, M.A.; Sohn, K. The Microbiota of the Extremely Preterm Infant. Clin. Perinatol. 2017, 44, 407-427. [CrossRef] [PubMed]

83. Niño, D.F.; Zhou, Q.; Yamaguchi, Y.; Martin, L.Y.; Wang, S.; Fulton, W.B.; Jia, H.; Lu, P.; Prindle, T., Jr.; Zhang, P.; et al. Cognitive impairments induced by necrotizing enterocolitis can be prevented by inhibiting microglial activation in mouse brain. Sci. Transl. Med. 2018, 10, eaan0237. [CrossRef] [PubMed]

84. Strunk, T.; Inder, T.; Wang, X.; Burgner, D.; Mallard, C.; Levy, O. Infection-induced inflammation and cerebral injury in pre-term infants. Lancet Infect. Dis. 2014, 14, 751-762. [CrossRef]

85. Volpe, J.J. Microglia: Newly discovered complexity could lead to targeted therapy for neonatal white matter injury and dysmaturation. J. Neonatal Perinatal Med. 2019, 12, 239-242. [CrossRef]

86. Volpe, J.J. Postnatal Sepsis, Necrotizing Entercolitis, and the Critical Role of Systemic Inflammation in White Matter Injury in Premature Infants. J. Pediatr. 2008, 153, 160-163. [CrossRef]

87. Gehrmann, J.; Matsumoto, Y.; Kreutzberg, G.W. Microglia: Intrinsic immuneffector cell of the brain. Brain Res. Rev. 1995, 20, 269-287. [CrossRef]

88. Ransohoff, R.M.; Perry, V.H. Microglial physiology: Unique stimuli, specialized responses. Annu. Rev. Immunol 2009, 27, 119-145. [CrossRef]

89. Shelby, R.D.; Janzow, G.E.; Mashburn-Warren, L.; Galley, J.; Tengberg, N.; Navarro, J.; Conces, M.; Bailey, M.T.; Goodman, S.D.; Besner, G.E. A novel probiotic therapeutic in a murine model of Clostridioides difficile colitis. Gut Microbes $2020,12$. [CrossRef] [PubMed] 